\title{
Caracterização química dos agregados e sedimentos superficiais na zona de máxima turbidez no complexo estuarino de Paranaguá (CEP)
}

\author{
Chemical characterization of aggregates and superficial sediments in the zone of maximum turbidity \\ of the Paranaguá Estuarine Complex (PEC) \\ CARLA GAMBAGORTE MACHADO* \\ * UFPR - Programa de Pós-Graduação em Geologia. calohah@hotmail.com
}

\begin{abstract}
Resumo
A investigação da estrutura físico-química da coluna de água em ponto fixo localizado na zona de máxima turbidez do Complexo Estuarino de Paranaguá permitiu avaliar a qualidade da água no período estudado. $\mathrm{O}$ pH sofreu baixa variação, de 7,47 a 8,04, a

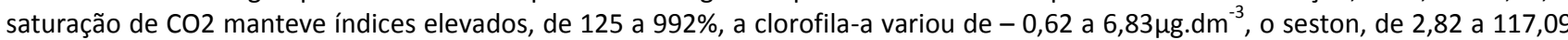
$\mathrm{mg} \cdot \mathrm{dm}-3$, e o oxigênio dissolvido, de 5,61 a $8,10 \mathrm{mg} \cdot \mathrm{dm}^{-3}$. Os nutrientes inorgânicos dissolvidos apresentaram as seguintes concentrações: fosfato, 0,33 a 3,28 $\mu \mathrm{mol} . \mathrm{dm}^{-3}$; silicato, 7,14 a 70,41 $\mu \mathrm{mol} . \mathrm{dm}^{-3}$; nitrato, 0,03 até $34,78 \mu \mathrm{mol} . \mathrm{dm}^{-3}$, nitrito, 0 a 1,12 $\mu \mathrm{mol} . \mathrm{dm}^{-3}$; e nitrogênio amoniacal, 0,08 a 7,95 $\mu \mathrm{mol} . \mathrm{dm}^{-3}$. O fósforo orgânico total ostentou valores de 0,33 a 4,73 $\mu \mathrm{mol} . \mathrm{dm}^{-3}$, enquanto que o nitrogênio orgânico total variou de 8,28 a $28,66 \mu \mathrm{mol} \cdot \mathrm{dm}^{-3}$. De modo geral, a qualidade da água segundo dados da literatura que estudaram sistemas estuarinos é boa, enquadrando-se dentro dos limites que não causam mal para a biota. Para os dois períodos (seco e chuvoso) a concentração dos agregados mostrou-se maior nas campanhas de sizígia encontrando-se na faixa de 19,2 a $299,5 \mathrm{mg} \cdot \mathrm{dm}^{-3}$, sendo que a estação verão ostentou os maiores valores devido às chuvas fortes que carregam material proveniente dos rios. Os elementos metálicos arsênio e cádmio não foram detectados nos agregados. Os sedimentos apresentaram concentrações normais para esses elementos, mostrando que o sistema não está contaminado. Notou-se através dos resultados das concentrações dos elementos estudados que o MPS é um importante agente na transferência de contaminantes metálicos para os sedimentos.
\end{abstract}

Palavras-chave: elementos metálicos; agregados; sedimentos superficiais

\begin{abstract}
The inquiry of the physical-chemical structure of the water column in a fixed point located in the zone of maximum turbidity of the Estuarine Complex of Paranaguá permitted to evaluate the water quality at the study period. The $\mathrm{pH}$ suffered low variation from 7,47 to 8,04 , the CO2 saturation kept high indices between 125 and $992 \%$, chlorophyll-a varied from - 0,62 to 6,83 g.dm ${ }^{-3}$, seston, 2,82 to $117,09 \mathrm{mg} \cdot \mathrm{dm}^{-3}$, and dissolved oxygen, 5,61 to $8,10 \mathrm{mg} \cdot \mathrm{dm}^{-3}$. The dissolved inorganic nutrients had presented the following concentrations: phosphate, 0,33 to $3,28 \mu \mathrm{mol} . \mathrm{dm}^{-3}$; silicate, 7,14 to $70.41 \mu \mathrm{mol} . \mathrm{dm}^{-3}$; nitrate, 0,03 to $34,78 \mu \mathrm{mol}^{\mathrm{dm}} \mathrm{dm}^{-3}$; nitrite, 0 to $1,12 \mu \mathrm{mol} . \mathrm{dm}^{-3}$; and ammoniac nitrogen, 0,08 to $7,95 \mu \mathrm{mol} . \mathrm{dm}^{-3}$. The total organic phosphor exhibited values between 4,73 and 0,33 $\mu \mathrm{mol} . \mathrm{dm}-3$ whereas the total lorganic nitrogen varied from 8,28 to $28,66 \mu \mathrm{mol} . \mathrm{dm}^{-3}$. In general, the quality of water according the literature of estuarine system is good, fitting inside the limits do not causing bad to biota. The concentration of aggregates revealed bigger in the campaigns of spring tide, from 19,2 to $299,5 \mathrm{mg} \cdot \mathrm{dm}^{-3}$ occurring the highest values in summer due to strong rain that load material from the rivers. The metallic elements $\mathrm{As}$ and $\mathrm{Cd}$ had not been detected at the aggregates. The sediments showed normal concentrations for these elements, indicated that the system is not been contaminated. It was noted that the elements studies, MPS are a important agent at the metallic elements transfer to bottom sediments. The work showed that the main way of transport of metallic contaminants is the suspension of particulate material.
\end{abstract}

Keywords: metallic elements; aggregates; superficial sediments 


\section{Introdução}

Os estuários são feições típicas costeiras localizadas na interface continente-oceano, influenciados fortemente pela ação das marés, possuindo extrema importância no estudo dos processos dinâmicos de transferência de material terrestre para o oceano (HILL, 1963; MIRANDA et al., 2002; SOUZA et al., 2005).

Os estuários sofrem influência direta e indireta de atividades urbanas, recreativas, portuárias, industriais, pesqueiras e de desmatamento (KNOX, 1986).

A contaminação no ambiente estuarino é provocada por lançamentos pontuais ou difusos de poluentes de origem industrial, agrícola e urbana. Dentre os diversos tipos de problemas ambientais decorrentes das atividades antrópicas em regiões portuárias, um dos mais graves é a contaminação por elementos metálicos. Esses poluentes associam-se à superfície das partículas sedimentares. São transportados associados ao material particulado em suspensão, dissolvidos na coluna de água ou por deposição atmosférica (SOLOMONS \& FÖRSTNER, 1984). Os sedimentos correspondem a um dos segmentos ambientais mais estáveis em termos físico-químicos, por isso seus parâmetros de caracterização química são ótimos indicadores de qualidade ambiental.

Os agregados (material particulado em suspensão), quando comparados com a água circundante, possuem maior concentração de nutrientes e elevada atividade microbiana. A sedimentação dos nutrientes é influenciada pela variação da maré que altera o gradiente de salinidade. Durante o processo de mistura da água doce com a marinha, grande parcela dos contaminantes pode sofrer processo de precipitação juntamente com a formação dos agregados. Assim, os agregados podem constituir uma via de transferência destes contaminantes da fração dissolvida para a particulada e em seguida para o sedimento de fundo.

O material particulado em suspensão não é utilizado para identificação de zonas contaminadas, porém é o principal meio de transporte dos poluentes metálicos e orgânicos, estando presente em todos os estuários.

Este trabalho procurou ampliar e consolidar a compreensão dos mecanismos e processos que atuam no transporte de material particulado em suspensão e contaminantes metálicos para os sedimentos depositados no fundo, na interface continente-oceano.

\section{2. Área de estudos}

\subsection{Localização}

O Complexo Estuarino da Baía de Paranaguá (CEP), situado na costa sul do Brasil, Paraná, entre $25^{\circ} 16^{\prime}$ e $25^{\circ} 34^{\prime}$ $S$ e $48^{\circ} 17^{\prime}$ e $48^{\circ} 42^{\prime} W$ (LANA et al., 2000), apresenta dois eixos: um na direção $\mathrm{E}-\mathrm{W}$, onde se situam as baías de Paranaguá e Antonina e outro na direção NNE-SSW, onde se situam as baías de Laranjeiras, Guaraqueçaba e Pinheiros (Figura 1).

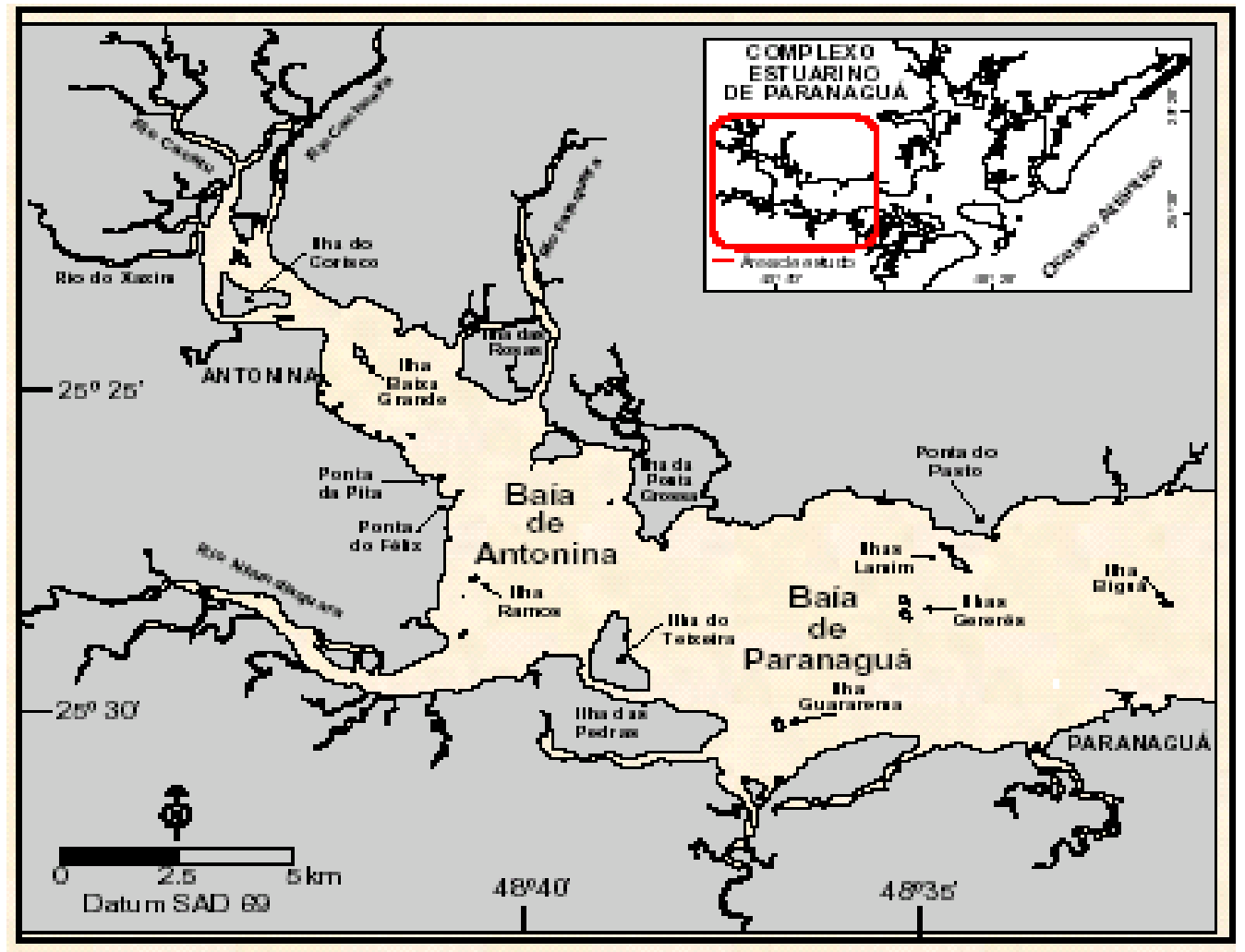

Figura 1. Complexo Estuarino da Baía de Paranaguá (CEP). 
O CEP possui área superficial de $601 \mathrm{~km}^{2}$, sendo 456 $\mathrm{km}^{2}$ margeados por manguezais, os quais constituem importante fonte de detritos para o sistema (REBELLO \& BRANDINI, 1990). O volume de água é da ordem de 2 x 109 $\mathrm{m}^{3}$ (KNOPPERS et al., 1987). Recebe uma descarga de água doce de $178{\mathrm{~m} 2 ~ \mathrm{~s}^{-1}}$, no período chuvoso (verão), e de $47 \mathrm{~m} 3$ s-1, no período seco (inverno) (MANTOVANELLI, 1999).

As baías de Antonina e Paranaguá (eixo E-W) possuem área de $258,4 \mathrm{~km}^{2}$, volume de $1,4 \times 109 \mathrm{~m}^{3}$ e extensão longitudinal de $50 \mathrm{~km}$ (KNOPPERS et al., 1987). Recebem a descarga dos rios Cachoeira, Faisqueira, Nhundiaquara e Guaraguaçu.

\subsection{Sedimentos: origem e composição}

A maior parte da planície costeira abrangente da baia de Paranaguá é composta por sedimentos quaternários depositados em ambientes marinhos, geralmente areias finas a muito finas, bem selecionadas e predominantemente quartzosas. Ocorrem ainda sedimentos arenosos e areno-argilosos, interpretados como paleoestuarinos, depositados em porções baixas e no fundo de antigos vales fluviais, ora afogados. Esses sedimentos provêm do continente ou do mar. Os sedimentos de origem continental associados a encostas (leques, tálus e colúvios) são compostos por cascalhos sustentados por matriz areno-argilosa, enquanto os de rios entrelaçados são formados predominantemente por areias quartzosas finas a muito finas (ANGULO, 1992).

\subsection{Circulação Estuarina}

A circulação nesses ambientes é regida basicamente por três fatores: a descarga de água doce, as correntes de maré e a tensão do vento. No caso da baía de Paranaguá, o principal mecanismo de fornecimento de energia para o sistema são as correntes de maré com influência do aporte fluvial (KNOPPERS al., 1987; MARONE \& CAMARGO, 1994), de caráter predominantemente semidiurno.

\subsection{Zona de Máxima Turbidez}

Uma das principais feições hidrodinâmicas dentro de um estuário é a zona de máxima turbidez (ZMT) que, quando comparada a zonas localizadas a jusante e a montante, caracteriza-se pela alta concentração de sedimentos em suspensão, cerca de 100 vezes maior (DAVIS, 1985; GRABEMANN et. al., 1989; DYER, 1995). Isso acontece porque existem condições ótimas para a floculação à medida que a descarga fluvial encontra a cunha de intrusão salina, o que aumenta o fluxo de deposição. Pode também ocorrer a ressuspensão dos sedimentos quando a corrente salina se arrasta junto ao fundo, colocando-os novamente na coluna de água, possivelmente desagregados, repetindo o processo (FERNANDES, 2001).

As ZMT são encontradas em estuários do mundo todo, independentemente do tamanho. Para o CEP, NOERNBERG
(2001) definiu a localização da ZMT entre as Ilhas Gererês e o Porto de Paranaguá.

\section{Materiais e métodos}

O presente estudo, enfocando o comportamento dos sedimentos em suspensão no CEP, envolveu medições in situ de propriedades físicas (salinidade, profundidade, condutividade) e coletas de amostras da coluna de água e de sedimentos para análise em laboratório.

As campanhas amostrais foram realizadas de acordo com a Tabela 1.

Tabela 1. Campanhas amostrais.

\begin{tabular}{cccc}
\hline \multicolumn{1}{c}{ Período } & Data & Maré & Amostras \\
\hline $\begin{array}{c}\text { Verão } \\
\text { (chuvoso) }\end{array}$ & $09 / 12 / 05$ & quadratura & $\begin{array}{c}\text { Água, MPS e } \\
\text { sedimento }\end{array}$ \\
& $16 / 12 / 05$ & sizígia & Água e MPS \\
\hline Seco (inverno) & $02 / 08 / 06$ & quadratura & $\begin{array}{c}\text { Água, MPS e } \\
\text { sedimento }\end{array}$ \\
& $08 / 08 / 06$ & sizígia & Água e MPS \\
\hline
\end{tabular}

As amostras de água de superfície e fundo foram tomadas com auxílio de uma garrafa de Niskin em intervalos de $2 \mathrm{~h}$, na estação âncora (ponto fixo na ZMT). Os sedimentos superficiais foram amostrados nas marés de quadratura de verão e de inverno, com o auxílio de um busca-fundo tipo Petit-Ponar, em três estações de coleta: uma localizada na zona de turbidez máxima (estação âncora, Lat / Long $74^{\circ} 33.987^{\prime} / 7^{\circ} 17.806^{\prime}$ ), uma a montante (Lat / Long $07^{\circ} 33.413^{\prime} / 71^{\circ} 83.086^{\prime}$ ) e outra a jusante (Lat / Long $07^{\circ} 42.778^{\prime}$ / $71^{\circ} 78.518^{\prime}$ ).

Os métodos de análise seguem na Tabela 2

Tabela 2. Técnicas e métodos de análises.

\begin{tabular}{|l|l|}
\hline \multicolumn{1}{|c|}{ Variável } & \multicolumn{1}{|c|}{ Método de Instrumentação } \\
\hline Nutrientes inorg. dissolvidos & Grasshoff et al. (1983) \\
\hline Carbono org. particulado & $\begin{array}{l}\text { Strickland \& Parsons (1972), com } \\
\text { adaptação para final titrimétrico }\end{array}$ \\
\hline $\begin{array}{l}\text { Nitrogênio e fósforo (orgânicos } \\
\text { particulados e total) }\end{array}$ & Grasshoff et al. (1983) \\
\hline Oxigênio dissolvido & $\begin{array}{l}\text { Winkler modificado (Grasshoff et al., } \\
\text { 1983) }\end{array}$ \\
\hline Clorofila-a e feopigmentos & Strickland \& Parsons (1972) \\
\hline Material em Suspensão & Strickland \& Parson (1972) \\
\hline Alcalinidade e CO2 & Carmouze (1994) \\
\hline pH & pH-metro de campo (HANNA) \\
\hline Temperatura & Termômetro de mercúrio \\
\hline Salinidade & Refratômetro ATAGO \\
\hline $\begin{array}{l}\text { Manganês, Cádmio, Ferro e } \\
\text { Arsênio }\end{array}$ & Digestão Ácida / Absorção Atômica \\
\hline
\end{tabular}


A determinação das concentrações pseudototais de metais pesados foi feita a partir da digestão das amostras de material particulado utilizando $10 \mathrm{~mL}$ por amostra de água régia $(\mathrm{HCl}$ : $\mathrm{HNO} 3)$ na proporção $3: 1$, seguidas de aquecimento em chapa elétrica durante $3 \mathrm{~h}$ ou até a formação de sais úmidos, da filtragem em papel filtro faixa branca (marca Whatman) e da adição de água deionizada até o volume de $50 \mathrm{~mL}$. Para os sedimentos depositados no fundo adotou-se o mesmo método, porém com peneiramento a úmido (passante em malha 63 ? $\mathrm{m}$ ), seguido de secagem e maceração. Utilizou-se $0,5 \mathrm{~g}$ desse sedimento para a digestão. As extrações foram lidas no equipamento ICP OES, modelo Vista Pró- Varian (2000).

\subsection{Análise estatística}

Optou-se pela realização da análise dos componentes principais (PCA) da coluna de água com utilização do software Statistical Primer. Escolheu-se o PCA para a verificação do padrão sazonal com a fase das marés investigadas e suas inter-relações, o qual supera problemas intrínsecos que ocorrem ao processar os dados como: dimensionalidade, colinearidade, ruído e a lacuna de alguns dados. Para a elaboração dos gráficos e da matriz de correlação (sedimentos superficiais), foi usado o software Statistic versão 6.0 .

\section{Resultados e discussão}

\subsection{Variáveis físicas}

As campanhas amostrais realizadas no verão apresentaram temperaturas de $24,76^{\circ} \mathrm{C}$ a $26,27^{\circ} \mathrm{C}$, sendo que a maior amplitude de variação $\left(1,51^{\circ} \mathrm{C}\right)$ ocorreu durante a maré de sizígia. Em contraste, nas campanhas de inverno, a temperatura da água exibiu maior estabilidade térmica, com valores entre 21,07 e $22,16^{\circ} \mathrm{C}$ (amplitude de variação de $1,09^{\circ} \mathrm{C}$ ).

Em ambientes estuarinos, a variação horizontal da temperatura é menor em relação às águas oceânicas, e apresenta pouca estratificação vertical devido à baixa profundidade, pois a ação dos ventos acaba misturando as águas e torna-as, assim, mais homogêneas.

No verão, a salinidade variou entre 18 e $27 \%$, com maiores valores nas amostras de fundo, durante as marés enchentes. Nas campanhas de inverno, a salinidade oscilou de 27 até 31, também com valores maiores nas amostras de fundo e menores nas de superfície.

A distribuição da salinidade indicou presença de águas mais salinas durante as enchentes nas campanhas de inverno. ABRAHÃO (2000), estudando a região eu-halina da baía de Paranaguá, obteve dados de comportamento semelhante, com valores maiores durante o inverno. Esse fato de as águas mostrarem-se menos salinas no verão é descrito por PRITCHARD (1967), e atribuído à maior ocorrência de chuvas nessa estação, o que tende a diluir as águas do estuário.
No presente estudo, essa variação ocorreu dentro das expectativas, já que a penetração da cunha salina durante a enchente adentra no estuário pela parte inferior, devido à maior densidade e, com a entrada da água marinha, o estuário tende a ficar mais salino.

Segundo KNOPPERS et. al. (1987) e MARONE (1995), o CEP é classificado como parcialmente misturado, do tipo $B$ (Figura 7), apresentando um gradiente halino horizontal com maiores valores próximo à desembocadura e menores valores na região de Antonina.

Todas as variáveis físicas investigadas evidenciaram influência direta das marés. Na campanha de verão, essa variação entre a sizígia e a quadratura foi menos perceptível enquanto que na campanha de inverno, a quadratura apresentou variação mais acentuada, que a sizígia.

\subsection{Coluna de água}

Os resultados do presente estudo foram comparados com dados obtidos por outros autores que estudaram a mesma área, com estudos de outras áreas e com os limites das variáveis ambientais estabelecidos pela Resolução 357/05 do Conama para diversas classes de águas (doces, salobras e salinas).

A Tabela 3 apresenta limites classificatórios para qualidade de água estuarina baseada em LIKENS (1975), RAST \& LEE (1978), NIXON (1995) e CARMOUZE (1994).

De maneira geral, as variáveis apresentaram-se dentro dos limites estabelecidos pelos autores na Tabela 3 e pelo Conama 357/05.

Tabela 3. Limites citados para classificação da qualidade d' água para estuários.

\begin{tabular}{cc}
\hline Indicador & Limites Considerados \\
\hline $\mathrm{pH}$ & $6,5-9,0$ \\
Saturação de $\mathrm{CO}_{2}(\%)$ & $<100$ \\
Oxigênio dissolvido $\left(\mathrm{mg}^{-3} \mathrm{dm}^{-3}\right)$ & $>6,5$ \\
Clorofila-a $\left(\mu \mathrm{gg} \cdot \mathrm{dm}^{-3}\right)$ & $1-10$ \\
Ortofosfato $\left(\mu \mathrm{mol} / \mathrm{dm}^{-3}\right)$ & $<31$ \\
Amônio $\left(\mu \mathrm{mol} / \mathrm{dm}^{-3}\right)$ & $20-30$ \\
Nitrato $\left(\mu \mathrm{mol} / \mathrm{dm}^{-3}\right)$ & $10-100$ \\
\hline
\end{tabular}

$\mathrm{O} \mathrm{pH}$, classificado como "normal", apresentou pequena redução nas águas com menores valores de salinidade. 0 fato de os índices de $\mathrm{CO} 2$ registrados serem elevados explica a baixa do $\mathrm{pH}$ ocorrido no inverno e ainda caracterizam a zona de máxima turbidez como um sistema predominantemente heterotrófico nas estações estudadas.

A clorofila ostentou maiores concentrações durante os períodos de águas de menor salinidade, o que mostra a importância do aporte continental de nutrientes para o incremento da biomassa fitoplanctônica. O seston relacionou-se inversamente à clorofila-a, fato explicado pela redução da fotossíntese enquanto o material particulado em suspensão apresentava-se mais alto e limitava assim a penetração da luz. Outro fator que impede a floração do fitoplâncton é o curto tempo de renovação 
das águas, de aproximadamente 3 a 4 dias (MARONE et al., 1995).

Os resultados de supersaturação do oxigênio dissolvido indicam que o oxigênio presente na água no momento das campanhas, tanto de verão quanto de inverno, suprem as necessidades da comunidade pelágica.

Os resultados encontrados para os nutrientes fosfato $\left(\mathrm{PO}_{4}{ }^{3-}\right)$, nitrato $\left(\mathrm{NO}_{3}{ }^{-}\right)$, nitrito $\left(\mathrm{NO}_{2}{ }^{-}\right)$, silicato $\left(\mathrm{Si}(\mathrm{OH})_{4}{ }^{-}\right)$e amônia $\left(\mathrm{NH}_{4}^{+}\right)$demonstraram uma variabilidade sazonal muito pequena. Entretanto, ao contrário do relatado por outros estudos (KNOPPERS et al., 1987, MACHADO et al., 1997, LANA et al., 2000), os maiores valores para os nutrientes ocorreram durante o inverno, salvo fosfato e nitrito, ambos maiores na maré de quadratura do verão. Isto mostra o papel da drenagem continental sobre o padrão dessas variáveis, ocasionado pelas chuvas, e evidencia a variabilidade interanual, como também verificado por BRANDINI (2000).

Os resultados de NPT mostram razões N:P acima da razão de Redfield, salvo sete amostras de inverno e duas de verão. A média para as campanhas do período chuvoso ficou em 23, e, no período seco, em 18, o que mostra proximidade com a proporção 16:1 átomos (Redfield). EÇA et al. (2006) encontraram valores para a razão N:P do estuário do rio Cachoeira em Ilhéus, Bahia, sempre acima dessa razão, com média de 42, o que, segundo estes autores, constituiu evidência de eutrofização do ambiente.
Tais valores foram devidos às elevadas concentrações de nitrogênio, o que não ocorreu no CEP.

De acordo com as variáveis investigadas e descritas acima, os resultados de suas concentrações podem ser visualizados na Figura 2.

A análise de componentes principais (PCA) revelou uma variação temporal bem definida, em caráter sazonal e em fase com ciclos de maré (Figura 2). Como pode ser observado, o eixo 1 definiu a separação entre os períodos de inverno e verão, associada principalmente à temperatura (auto-vetor $=0,38$ ) e à clorofila, com uma variância capturada de 40,7\%. O eixo 2 separou as campanhas de quadratura e sizígia do verão em dois grupos (variância capturada de 15,2\%), associando as amostras de água coletadas na sizígia às variáveis silicato, $\mathrm{CO} 2$ e oxigênio, e a campanha de quadratura a fosfato, pH e seston. As campanhas realizadas no inverno apresentaram forte associação com os nutrientes inorgânicos dissolvidos, NOT e POT, bem como com a salinidade, mas não apresentaram uma separação tão bem definida entre sizígia e quadratura como verificado para o verão. As campanhas de verão associaram-se principalmente à temperatura. Observa-se a influência que o pH exerce no silicato e oxigênio. Já a temperatura e a clorofila influenciam a amônia, a salinidade, o nitrito, o nitrato, a alcalinidade e o nitrogênio e o fósforo orgânicos totais.

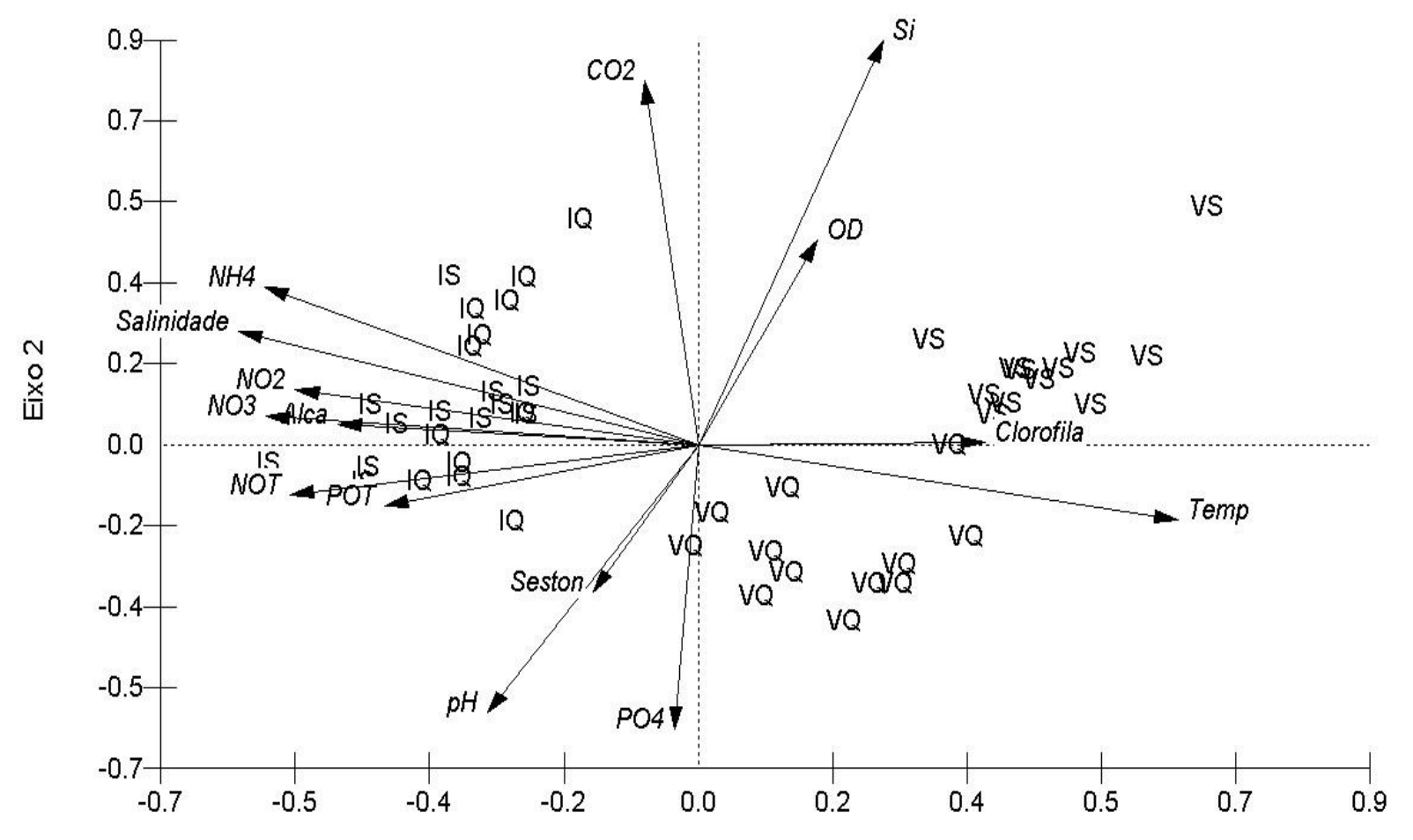

Vector scalina: 1.70

Eixo 1

Figura 2. Análise dos Componentes Principais (PCA) das amostras das campanhas de verão, na sizígia (VS) e na quadratura (VQ) e nas de inverno, na sizígia (IS) e na quadratura (IQ) do Complexo Estuarino da Baía de Paranaguá (CEP). 
Tabela 4. Resultados obtidos para as variáveis analisadas da coluna d’água no Complexo Estuarino de Paranaguá.

\begin{tabular}{|c|c|c|c|c|c|c|c|c|c|c|c|c|}
\hline \multirow{2}{*}{$\begin{array}{l}\text { Estação } \\
\text { Verão }\end{array}$} & \multirow{2}{*}{$\begin{array}{l}\text { pH } \\
7,48\end{array}$} & \multirow{2}{*}{$\begin{array}{l}\mathrm{CO2} \\
\% \\
217 \mathrm{a}\end{array}$} & \multirow{2}{*}{$\begin{array}{l}\begin{array}{l}\text { Clorofila- a } \\
\mu g \cdot d^{-3}\end{array} \\
0,85 \text { a } 6,83\end{array}$} & \multirow{2}{*}{$\begin{array}{l}\begin{array}{l}\text { Seston } \\
\text { mg.dm }\end{array} \\
2,62 \mathrm{a}\end{array}$} & \multirow{2}{*}{$\begin{array}{l}\begin{array}{l}\text { Oxigênio } \\
\text { Diddolvido } \\
\text { mg.dm }^{-3}\end{array} \\
6,47 \text { a } 8,10\end{array}$} & Fosfatc & icato/Ni & o/Nitrit & nônio $\mu \mathrm{m}$ & ol.dm & \multicolumn{2}{|c|}{$\begin{array}{l}\text { Fósforo /Nitrogênio } \\
\text { Orgânico Dissolvido } \\
\mu \mathrm{mol} . \mathrm{dm}^{-3}\end{array}$} \\
\hline & & & & & & $0,33 a$ & $7,14 \mathrm{a}$ & $0,03 a$ & 0 a 1,12 & $0,08 a$ & 0,33 a 1,47 & 17,44 a \\
\hline & a & 692 & & 81,01 & & 3,28 & 66,77 & 19,00 & & 1,77 & & 28,66 \\
\hline & 7,95 & & & & & & & & & & & \\
\hline \multirow[t]{3}{*}{ Inverno } & 7,47 & $125 a$ & $-0,62 \mathrm{a}$ & $18,49 \mathrm{a}$ & 5,61 a 7,61 & $0,40 \mathrm{a}$ & $17,46 \mathrm{a}$ & $7,45 \mathrm{a}$ & $0,41 \mathrm{e}$ & $2,89 \mathrm{e}$ & 0,68 a 4,73 & $8,29 \mathrm{a}$ \\
\hline & a & 992 & 6,33 & 117,09 & & 1,14 & 70,41 & 34,78 & 0,84 & 7,95 & & 24,93 \\
\hline & 8,04 & & & & & & & & & & & \\
\hline
\end{tabular}

\subsection{Agregados}

Na maré de quadratura de verão, o material particulado em suspensão apresentou concentrações variando de 26,3 a $45,8 \mathrm{mg} \cdot \mathrm{dm}^{-3}$ e, na sizígia, nesse mesmo período, de 187,3 a $299,5 \mathrm{mg} \cdot \mathrm{dm}^{-3}$. Durante as campanhas de inverno, na maré de quadratura houve uma variação de 19,2 a 89,6 $\mathrm{mg} \cdot \mathrm{dm}^{-3} \mathrm{e}$, na maré de sizígia, de 21,6 a 48,0 mg.dm ${ }^{-3}$.

A concentração de MPS obtida durante o ciclo de marés da campanha de verão e na sizígia apresentou valores maiores do que os encontrados em outros estuários estudados no mundo todo. Esta estação do ano é caracterizada por chuvas fortes que carregam material proveniente dos rios, resultado de erosão de margens e de ressuspensão dos sedimentos de fundo. A maré de sizígia é caracterizada pela grande influência das correntes de maré, tornando o ciclo mais intenso em relação às marés de quadratura. Na quadratura, as amostras mais carregadas de MPS foram colhidas durante marés enchentes. Durante essa amostragem, ocorreu a passagem de navios e dragas, colaborando para a ressuspensão dos sedimentos. MANTOVANELLI (1999) concluiu que mais de $50 \%$ do MPS presente na baía de Paranaguá é de origem fluvial, adentrando no estuário propriamente dito durante a vazante.

As concentrações de carbono orgânico particulado das campanhas de verão não sofreram grandes variações, oscilando de 13,08 a 16,63 mg C.g ${ }^{-1}$, extraído o valor outlier de 4,25 mg C.g ${ }^{-1}$.

Para a maioria das amostras do particulado, o limite de detecção adotado não apresentou a sensibilidade esperada. O As apresentou concentrações menores que 2,0 mg. $\mathrm{kg}^{-1}$ e o $\mathrm{Cd}$, concentrações predominantemente menores que $0,2 \mathrm{mg} \cdot \mathrm{kg}^{-1}$.

Os comportamentos do Fe e Mn particulados mostram que a remobilização dos sedimentos de fundo por ressuspensão e bioturbação sentido montante podem liberar $\mathrm{Mn}$ e Fe dissolvidos para a coluna de água. O Fe dissolvido é rapidamente oxidado nas águas de fundo, produzindo uma camada de óxido de ferro. O Mn oxida mais lentamente que o Fe em sistemas naturais.

\subsection{Sedimentos superficiais}

A origem e a composição dos sedimentos superficiais apresentam influências diferentes em cada porção do estuário. Na porção à montante, localizada na baía de
Antonina, estes sedimentos sofrem grande influência fluvial e são de composição heterogênea (granulometria) sendo que a porcentagem de finos é superior em relação às demais porções do estuário. No setor intermediário, a influência é fluvial e marinha, porém com menor porcentagem de finos; o setor inferior (jusante), composto por areia fina a muito fina, delimita a área de influência da desembocadura (SOARES et al., 1996).

O comportamento dos sedimentos mostrou-se atípico (Tabela 5) para as variáveis: carbono orgânico total (COT), clorofila-a e nutrientes (fósforo e nitrogênio orgânicos totais) com os maiores valores no período seco de inverno. Possíveis explicações para tal discrepância são as chuvas ocorridas em dias antecedentes às coletas, as quais podem funcionar como um mecanismo de incremento no aporte de matéria orgânica e de nutrientes. Esses valores estão acima do que dita o Conama 344/04 para sedimentos. Esta resolução apresenta valores referência para contaminação de sedimentos.

Tabela 5. Resultados de COT (\%), POT (mg.kg-1) e NOT (mg.kg ${ }^{-1}$ ) para os sedimentos e seus respectivos valores alertas ditados pela legislação do CONAMA 344/04.

\begin{tabular}{ccccc}
\hline Ponto & Período & $\begin{array}{c}\text { COT (\%) } \\
\text { *Valor } \\
\text { alerta = 10 }\end{array}$ & $\begin{array}{c}\text { POT }\left(\mathrm{mg} . \mathrm{kg}^{-1}\right) \\
\text { *Valor alerta }= \\
\mathbf{2 0 0 0}\end{array}$ & $\begin{array}{c}\text { NOT }\left(\mathrm{mg} . \mathrm{kg}^{-1}\right) \\
\text { *Valor alerta } \\
\mathbf{4}\end{array}$ \\
\hline Jus00 \\
Montante 1 & Verão & $\mathbf{2 , 3 8}$ & 1958,27 & 7109,34 \\
Ponto Fixo 1 & Verão & 0,49 & 3273,29 & 8911,84 \\
Jusante 2 & Verão & 1,7 & 10076,24 & 16172,98 \\
Montante 2 & Inverno & 16,42 & 17279,71 & 22559,32 \\
Ponto Fixo 2 & inverno & 14,90 & 13296,52 & 16562,42 \\
\hline
\end{tabular}

O fósforo ostentou maiores concentrações quando a salinidade apresentou menores valores (quadratura de inverno). GOMES et al. (2000) mostraram em um estudo realizado no estuário do Rio Vaza-Barris (SE) que o fósforo orgânico apresentou maiores concentrações em regiões de baixa salinidade, com forte correlação com o ferro.

Os teores de clorofila-a nos sedimentos superficiais durante o verão foram de $0,44 \mathrm{mg} \cdot \mathrm{g}^{-1}$ a jusante, $0,30 \mathrm{mg} \cdot \mathrm{g}^{-1}$ a montante e $0,88 \mathrm{mg} \cdot \mathrm{g}^{-1}$ na estação âncora. Para o inverno, obtiveram-se 5,74 mg.g $\mathrm{g}^{-1}$ a jusante, $1,97 \mathrm{mg} \cdot \mathrm{g}^{-1}$ a montante e $2,62 \mathrm{mg} \cdot \mathrm{g}^{-1}$ na estação âncora. O fato dos maiores valores ocorrerem no inverno pode ser decorrente de condições meteorológicas mais favoráveis aos processos de deposição da biomassa fitoplanctônica no período de 
inverno ou a um incremento nas taxas de produção microfitobêntica.

A Tabela 6 apresenta os resultados dos elementos $\mathrm{Cd}$, As, Fe e Mn quantificados no equipamento ICP OES.

Tabela 6. Concentração dos metais $\mathrm{Cd}$, As, Fe e $\mathrm{Mn}$ dos sedimentos superficiais na ZMT, em mg. $\mathrm{kg}^{-1}$, nas campanhas de quadratura no verão (1) e inverno (2).

\begin{tabular}{ccccc}
\hline Ponto & Cd & As & Fe & Mn \\
\hline Jusante 1 & 0,8 & 9,7 & 17943,1 & 232,1 \\
Montante 1 & 1,29 & 15,2 & 22025,8 & 293,0 \\
Ponto Fixo 1 & 0,5 & 9,7 & 20333,0 & 340,0 \\
Jusante 2 & 0,8 & 10,5 & 19488,0 & 595,3 \\
Montante 2 & 0,89 & 10,6 & 20517,9 & 444,1 \\
Ponto Fixo 2 & 0,8 & 10,7 & 18909,0 & 430,5 \\
\hline
\end{tabular}

O As e o Cd não apresentaram risco para a biota. As concentrações de As em sedimentos marinhos e estuarinos não contaminados normalmente variam de 5 a $15 \mathrm{mg} . \mathrm{kg}^{-1}$ em peso seco (MOORE \& RAMAMOORTHY, 1984 apud SÁ, 2003). As amostras localizadas a montante ostentaram concentrações maiores para os dois elementos, as quais podem provir em parte das atividades desenvolvidas no Terminal Portuário da Ponta do Félix.

Os sedimentos de superfície na área estudada apresentaram altos teores de Fe e Mn. Na campanha de verão, o Fe mostrou-se mais abundante que $\mathrm{Mn}$, enquanto que na campanha de inverno o $\mathrm{Mn}$ manteve maiores valores. A ausência de correlação entre Fe e Mn (Tabela 6) deve-se provavelmente ao fato de que o manganês seja mobilizado mais rapidamente que o ferro, pela redução do Eh ,como relatado para a baía de Sepetiba (ARAGON et. al., 1986). As concentrações de Fe e $\mathrm{Mn}$ tendem a ser mais elevadas como conseqüência do ciclo de oxi-redução provocado pela decomposição de matéria orgânica.

\section{Considerações finais}

O principal processo atuante no transporte do material particulado em suspensão certamente é o ciclo de marés que condiciona a erosão, ressuspensão e sedimentação. As concentrações de MPS durante as quatro campanhas evidenciaram tal afirmação durante as marés de sizígia e na vazante, devido a maior influencia fluvial, além da baixa profundidade deste estuário e a elevada variação da amplitude

Durante o período de realização do projeto, os resultados das concentrações dos elementos metálicos As e Cd não apresentaram danos para o ambiente, porém devese sal;ientar que a área estudada está localizada na zona de influência dos portos de Paranaguá e Antonina, fato que pode interferir na concentração desses elementos já que essa região desenvolve atividades impactantes ao ambiente.

Agradecimentos: À Dra Eunice C. Machado, ao Dr. Sambasiva Rao Patchineelam e à CAPES.

\section{Referências bibliográficas}

ABRAHÃO R.L.B.E.2000. "Variabilidade diária do zooplâncton e de descritores ambientais no setor euhalino da Baía de Paranaguá no verão e inverno de 1996". Dissertação de mestrado 9Curso de Pós-graduação em Ciências Biológicas) Setor de Ciências Biológicas. UFPR : Curitiba.

ANGULO R.J. 1992. "Geologia da planície costeira do Estado do Paraná." Instituto de Geociências, Universidade de São Paulo, São Paulo, Tese de Doutorado, 334p.

ARAGON G.T., PIRES V.S., LACERDA L.D., PATCHINEELAM S.R. 1986. "Distribuição espacial de nutrientes e metais pesados em sedimentos e águas superficiais em um ecossistema de manguezal". Acta Limnol. Brasil. 1, 365- 385.

BRANDINI N. 2000. "Variação espacial e sazonal da produção primária do fitoplâncton em relação às propriedades físicas e químicas na Baía das Laranjeiras e áreas adjacentes do complexo estuarino da Baía de Paranaguá (Paraná - Brasil)." Dissertação de Mestrado (Departamento de Botânica) Universidade Federal do Paraná, Curitiba, Brasil.

BRICKER S.B., FERREIRA J.G., SIMAS T. 2003. "An integrated methodology for assessment of estuarine trophic status." Ecological Modelling. 169, 36-60.

CARMOUZE J.P. 1994. O Metabolismo dos Ecossistemas Aquáticos: Fundamentos Teóricos, Métodos de Estudo e Análises Químicas. Editora Edgard Blücher : FAPESP. 253 p.

Conama - Conselho Nacional do Meio Ambiente. Resolução no344 de 25 de março de 2004.
CONAMA - Conselho Nacional do Meio Ambiente. Resolução no 357 de 17 de março de 2005.

DAVIS Jr., RICHARD A. 1985. "Coastal Sedimentary Enviroment". 2n Edition. Springer-Verlag. 716 pp.

DYER K.R. 1995. "Sediment transport processes in estuaries". In: Geomorphology and Sedimentology of Estuaries, G.M.E. Perillo (ed.). Developments in Sedimentology, 53. Elsevier Science, 423-449.

FERNANDES L.D.F. 2001. "Transportes de poluentes em estuários". Dissertação final do Curso de licenciatura em Engenharia do Ambiente. Universidade Técnica de Lisboa. 54p.

GOMES V.R., ALVES J.P.H., GARCIA C.A.B., COSTA JÚNIOR N.B., SANTOS E. 2000. "Distribuição de fósforo em sedimento do Estuário do Rio Vaza - Barris / SE". Departamento de Química da Universidade Federal de Sergipe. 3p.

GRABEMANN I., KRAUSE G. "Transport Processes of Suspended Matter Derived from Time Series in a Tidal Estuary". Journal of Geophysical Research, Federal Republic of Germany, 15 out. 1989. 94, 14,373-14,379.

HILL M.N. 1963. "The Sea". v.2, Interscience Publishers. 306-324.

KNOPPERS B.A., BRANDINI F.P., THAMM C.A. 1987 . "Ecological studies in the Bay of Paranaguá". II. Some physical and chemical characteristics. Nerítica, Curitiba,2 (1), 1-36.

KNOX G.A. 1986. "Estuarine ecosystems: A systems approach", vol.I, 289p.

LANA P.C., MARONE E., LOPES R.M., MACHADO E.C. 2000. "The subtropical estuarine complex of Paranaguá Bay, Brazil." In: 
Ecological Studies, Coastal Marine Ecosystems of Latin America. Springer-Verlag Berlin Heidelberg, 144, 131-145.

LIKENS G.E. 1975. "Primary production of inland aquatic systems." In: H. Lieth \& R. H. Whittaker (eds), Primary Productivity of the Biosphere, Springer Verlag, Berlin, 185-202.

MACHADO E.C., DANIEL C.B., BRANDINI N., QUEIROZ R.L.V. 1997. "Temporal and spatial dynamics of nutrients and particulate suspended matter in Paranaguá Bay, PR, Brasil". Nerítica, 27, $17-36$.

MANTOVANELLI A. 1999. "Caracterização da dinâmica hídrica e do material particulado em suspensão na Baía de Paranaguá e em sua bacia de drenagem." Dissertação de Mestrado em Geologia Ambiental, UFPR, 152p.

MARONE E., GUIMARÃES M.R.F., CAMARGO R., PRATA Jr. V.P., KLINGENFUSS M.S. 1995. "Caracterização física das condições oceanográficas, meteorológicas e costeiras das zonas estuarinas da Baía de Paranaguá." VI Congresso Latino Americano de Ciências do Mar, Mar del Plata, Argentina.

MIRANDA L.B., CASTRO B.M., KJERFVE B. 2002. "Princípios de Oceanografia Física de Estuários". Ed. Da USP. 408 pp.

MOORE J.W., RAMAMOORTHY S. 1984. "Heavy metals in natural waters. "Applied Monitoring and Risk Assessment. Springer Verlag, New York, NY, USA.

NIXON S.W. 1995. "Coastal marine eutrophication: a definition, social causes and future concerns." Ophelia 41: 199-219 p.

NOERNBERG, M. A. 2001. "Processos morfodinâmicos no Complexo Estuarino de Paranaguá - Paraná - Brasil: um estudo a partir de dados in situ e Landsat - TM". Programa de PósGraduação em Geologia, Universidade Federal do Paraná, Curitiba, Tese de Doutorado, $180 \mathrm{p}$.

PRITCHARD D.W. 1967. "What is a estuary. Physical viewpoint." In: LAUFF, G. H. ed Estuaries. Washington, American Association for the Advance of Science, 3-5.

RAST W., LEE G.F. 1978. "Summary analysis of the North American OCED Eutrophication project: nutrients, loading-lake response relationships and trophic site indices." Report EPA - 600/3-78008, U.S. Environmental Protection Agency, Duluth, MN.

REBELLO J., BRANDINI F. P. 1990. "Variação temporal de parâmetros hidrográficos e material particulado em suspensão em dois pontos fixos da Baía de Paranaguá Paraná (junhgi/87fevereiro/88)." Nerítica 5, 95-111.

SÁ F. 2003 "Distribuição e Fracionamento de Contaminantes nos Sedimentos Superficiais e Atividades de Dragagem no Complexo Estuarino da Baía de Paranaguá (PR)." Tese (Mestrado em Geologia Ambiental) - Departamento de Geologia do Setor de Ciências da Terra. Curitiba: Universidade Federal do Paraná.

SOARES P.C., ROSTIROLLA S.P., FERREIRA F.J.F., STEVANATO R. 1996. "O alto estrutural Pitanga-Quatiguá-Jacutinga na Bacia do Paraná: Uma Estrutura Litosférica." In: ong. Brás. Geol., 39 Salvador 1996. Anais...Salvador, SBG. 5, 411-414.

SOLOMONS W., FORSTNER U. 1984. "Metals in the Hidrocycle". Berlin: Springer - Verlag 349p.

SOUZA C.R.G., SUGUIO K., OLIVEIRA A.M.S., OLIVEIRA P.E. 2005."Quaternário do Brasil". Holos Ed., 378 pp. 